\author{
Heloisa Buarque de Almeida
}

Universidade de São Paulo, São Paulo, SP, Brasil

\title{
Educação do corpo: o seriado Mulher e a promoção de mensagens médico-educativas
}

Resumo: O artigo apresenta uma reflexão sobre o seriado Mulher, exibido pela Rede Globo entre 1998 e 1999, dirigido ao público feminino e que concentrava uma intensa programação do chamado merchandising social voltado a temas médicos e preventivos. Através da narrativa sobre duas ginecologistas, o seriado tanto desenvolvia histórias melodramáticas e cômicas, como promovia intensamente uma série de mensagens voltadas aos temas da saúde feminina, valorizando noções de medicalização e cuidados com o corpo. O trabalho explora dois aspectos: parte do contexto (social e da emissora) em que se insere Mulher e como questões médicas e de tecnologia são apresentadas. Para interpretar o conteúdo do seriado, busca refletir sobre o merchandising e o uso de certa estrutura narrativa do melodrama que facilitaria um tom pedagógico, visando promover práticas de cuidado.

Palavras-chave: mídia, teledramaturgia, gênero, saúde, mensagens sociais.

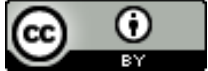

Esta obra está sob licença Creative Commons.

1 Esta pesquisa já contou com auxílios do CNPq e da FAPESP. ${ }^{2}$ Sobre o início do merchandising nas telenovelas da Globo, cf. Renato ORTIZ, Silvia BORELLI e José Mário RAMOS (1989), e sobre o merchandising social, cf. Marcio SCHIAVO (2006); Hamburger (2005); Heloisa Buarque de ALMEIDA (2003); Antonio La PASTINA, Joseph STRAUBHAAR, Almeida (1999) e um mapeamento extenso das ações de merchandising social em telenovelas encontra-se na dissertação de Alejandra Pía NICOLOSI (2009).

\section{Introdução}

Este artigo busca entender alguns aspectos do seriado Mulher, exibido pela Rede Globo entre 1998 e 1999, inspirado em seriados médicos norte-americanos. ${ }^{1}$ Tratava-se de uma produção dirigida ao público feminino, visando atingir diversas faixas etárias e classe sociais, e que concentrava uma intensa programação do chamado merchandising social voltado a temas médicos e preventivos. Merchandising é o termo usado no Brasil para a colocação de anúncios comerciais em meio à narrativa ou ao programa, e o merchandising social refere-se à promoção de "valores sociais" considerados informativos e educativos. ${ }^{2}$ Através da narrativa sobre duas médicas (ginecologistas e obstetras) e suas vidas pessoais, profissionais, e ambientado numa clínica particular que também atendia pacientes do sistema público num ambulatório de atenção primária, o seriado tanto 
${ }^{3}$ O seriado foi gravado em DVD e as histórias foram fichadas e sistematizadas de forma a viabilizar uma interpretação a partir de muitas horas de gravação. Agradeço à Cristiane Paião Macedo a organização e sistematização do material empírico do seriado, através de bolsa de Treinamento Técnico da FAPESP. desenvolvia histórias melodramáticas e cômicas, como promovia intensamente uma série de mensagens consideradas educativas e preventivas em temas da saúde feminina. Por meio da repetição exaustiva sobre a necessidade de exames periódicos, atitudes preventivas, planejamento familiar, uso de preservativos, entre outros temas, o seriado valorizava noções de medicalização e cuidados com o corpo e a saúde.

Discuto alguns aspectos do seriado: por um lado, entender sucintamente o contexto em que se insere e por que foi produzido; por outro, analisar como questões médicas e de tecnologia médica foram então apresentadas, e como seu tom era pedagógico. No primeiro aspecto, há tanto um contexto social e médico do período (relacionado à quantidade de partos normais e cesáreas no país), como, também, uma proposta para entender como se deu a sua produção.

Mulher insere-se num debate mais amplo, visibilizado pela mídia na segunda metade dos anos 1990 sobre a questão do excesso de partos cesáreos no país. Com isso, quero afirmar que essa teledramaturgia tem uma atuação pública relacionada a vários temas políticos da nação, como afirma Esther HAMBURGER (2005). Outro aspecto que merece destaque e é explicativo do conteúdo do seriado revela-se no processo de tentativa de reformulação da imagem pública da Globo através do marketing social. É no momento em que os profissionais da mídia reconhecem que há uma "influência" da TV em termos de práticas e comportamentos das suas audiências que esta emissora passa a promover mensagens socioeducativas nas narrativas como parte de uma estratégia de marketing empresarial, visando melhorar a imagem da emissora.

Buscando entender o conteúdo do seriado com foco nestas mensagens educativas, recorri às imagens dos 60 episódios ${ }^{3}$ e encontrei certa estrutura narrativa geral que era aplicada aos merchandisings sociais. Retomo, brevemente, a narrativa mais longa e telenovelesca da série (seus dois anos), que expressa construções de gênero recorrentes na teledramaturgia da Globo no período, associada a certo ideal de protagonista trabalhadora, profissional, em busca do amor, sincera e transparente em suas intenções. É possível entender melhor seu empenho "civilizatório", nos termos de Norbert ELIAS (1994), na direção de uma educação social do corpo, ao se levar em conta o caráter pedagógico que parece permear as narrativas com tom melodramático.

Alguns trabalhos refletiram sobre como o formato do melodrama se tornou uma produção tipicamente feminina na indústria cultural, que tratava de temas considerados femininos, tais como as relações amorosas e familiares, com 
${ }^{4}$ Evidentemente que não considero possível imaginar uma época "moderna" por oposição a uma época religiosa, como parece oferecer a interpretação de Brooks. Ainda assim, sua sugestão de perceber uma matriz didática na narrativa dramática me parece produtiva. determinados clichês e convenções narrativas, mas aberto a temáticas muito diversas. No entanto, a maior parte desses trabalhos está voltada para filmes considerados lacrimosos, como o cinema latino-americano discutido por Silvia OROZ (1992), os filmes femininos de Hollywood (Christine GLEDHILL, 1987) ou as soap operas norte americanas e inglesas (Tania MODLESKI, 1982, Hobson, 1982). Ali, há certos padrões narrativos mais fixos, tais como amores impossíveis, filhos órfãos em busca de sua verdadeira origem, mães solteiras que buscam se redimir através, muitas vezes, do sacrifício, e vilões personificados que atuam de modo maligno e planejado (cf. Marlise MEYER, 1996, no caso do folhetim). Certamente, são, também, melodramas no sentido de que a música de fundo compõe de modo marcante a narrativa - por exemplo, a associação entre um personagem e uma canção, ou o clima de suspense que pode preparar a entrada de um "vilão".

Uso o termo melodrama a partir das contribuições de Peter BROOKS (1976) e da forma como sua reflexão sobre a literatura é transposta para o cinema e a televisão na análise feita por Ismail XAVIER (2000 e 2003). Brooks propõe uma análise da literatura que percebe uma "imaginação melodramática" por trás de narrativas consideradas "realistas" (como as de Henry James e Balzac), ou seja, narrativas que aparentariam estar fora do padrão clássico do melodrama, se comparadas ao teatro francês que dá origem ao termo (Jean-Marie THOMASSEAU, 1989). Para Brooks, o melodrama é um formato com certo caráter pedagógico típico de uma sociedade pós-sagrada (moderna). ${ }^{4}$ Outras análises sobre 0 melodrama (THOMASSEAU, 1989 e MEYER, 1996) já ressaltaram seu caráter pedagógico. Para Brooks, a base do melodrama consiste num drama moral, que toma o comum, o ordinário e a vida privada como tema, classifica entre o bem e o mal, e faz uma narrativa de embates cuja moral final traz uma "cola social" necessária, repõe valores comuns. Ou seja, o melodrama tende a ter uma "mensagem" final sobre como agir "corretamente" e ao lado do "bem" - e é nesse sentido que se percebe seu tom pedagógico.

É a partir dessa noção mais alargada de melodrama, inspirada, também, em Brooks, que len ANG (1985, 1990 e 1996) propõe interpretar a relação das espectadoras com seriados norte-americanos, como Dallas, e o quanto esse tom moral que os caracteriza geraria certas identificações afetivas com as audiências. Ou seja, é nas identificações das espectadoras com determinadas personagens e tramas que os melodramas seriados permitem e criam certo envolvimento afetivo. Como argumentei, também, por essa identificação, que a telenovela geraria certa reflexividade nos espectadores, que refletiriam a partir dos personagens 
${ }^{5}$ Sobre a mídia como uma esfera de construção de gênero, cf. Teresa De LAURETIS (1994), que é a inspiração subjacente ao meu interesse em estudar os teledramas femininos.

\footnotetext{
- Ao longo dos 61 episódios, foram 12 os autores: Adriana Falcão, Álvaro Ramos, Antonio Calmon, Doc Comparato, Flavia Lins e Silva, Euclydes Marinho, Geraldo Carneiro, Glória Perez, Lynn Mamet, Maria Adelaide Amaral, Maria Helena Nascimento, Rosane Lima. Dirigiram a Série Daniel Filho, José Alvarenga Júnior, Mário Márcio Bandarra, José Carlos Pieri e Cininha de Paula.
}

em suas vidas. Nesse sentido, trata-se de um drama moral que promove certos valores morais do que é certo ou errado, como agir, e que reforça construções de gênero promovidas na teledramaturgia. ${ }^{5}$ Não apenas onde pretende ser explicitamente didático, mas, também, pela geração dessa reflexividade no espectador, a teledramaturgia que se estuda aqui é marcada pela promoção de certa moral.

Vê-se um alargamento desse tom pedagógico ainda no caso deste seriado, em que o drama narrado visa, exatamente, promover certos tipos de valores e atitudes nas espectadoras ligadas à noção de saúde, cuidado e prevenção. Para tanto, usa, muitas vezes, a estratégia publicitária de demonstrar a eficiência daquilo que é promovido. A cada episódio, algumas pessoas que aderem ao tratamento médico se curam, garantindo o happy end.

O gênero narrativo, como o melodrama, também compartilha códigos e convenções com sua audiência, o que pode auxiliar a compreensão da linguagem e da narrativa. Basta certo tipo de olhar do ator, para saber se aquele personagem deve ser "do mal". Os personagens "do bem" são transparentes e revelam o que pensam e sentem. Na indústria de televisão, tais narrativas são repletas de clichês interpretativos, gestos faciais dos atores e músicas de fundo que compõem um jogo de sentidos. Serão as personagens "do bem", as protagonistas, as que ensinam, na narrativa, o modo correto de agir.

\section{Entretenimento recheado com mensagens socloeducativas sobre saúde (da mulher)}

Mulher foi um seriado exibido pela Rede Globo entre abril de 1998 e dezembro de 1999, compreendendo, ao todo, 60 episódios. A série contou com a consultoria de um grupo de médicos, e os autores brasileiros tiveram assessoria de uma escritora norte-americana especializada em seriados, Lynn Mamet. ${ }^{\circ}$ Cada episódio trazia dois núcleos de personagens com temas médicos, mas compreendia, também, uma terceira história, que fazia parte da narrativa dos personagens fixos. Esta história se desenvolve mais lentamente ao longo do seriado, com cuidadosa continuidade, e trata das peripécias das duas personagens centrais. São duas ginecologistas: a mais jovem, Dra. Cristina, é, logo no início da série, contratada pela diretora de uma clínica, de meia idade, Dra. Marta (interpretadas por Patrícia Pillar e Eva Wilma, respectivamente).

Os perfis distintos das heroínas pretendem atrair mulheres de diferentes gerações como audiência, que poderiam se identificar com cada uma delas. Sabemos que 
${ }^{7}$ Excepcionalmente, houve alguns dilemas que foram apresentados em 2 episódios, desenrolando-se um pouco mais lentamente. esta é uma preocupação presente na produção de séries e telenovelas, como contam os próprios autores da Globo (MEMÓRIA GLOBO, 2008; Renata PALLOTTINI, 1998). Além disso, essa afinidade é facilitada pela escolha de atrizes que já são queridas do público feminino. O imaginário em torno dessas atrizes (sua persona pública) foi muito usado para promover a série, tanto na publicidade da Globo, como nas matérias da imprensa escrita.

Com as duas médicas trabalhando juntas numa clínica particular que também faz atendimento ao sistema público em seu ambulatório (nos fundos de um elegante casarão onde funciona a clínica), a narrativa trazia uma profusão de mensagens de prevenção a diversas doenças, explicação de usos de métodos anticoncepcionais, casos de aborto, estupro, violência doméstica, além de enfatizar, também, os temas tradicionais do melodrama - como histórias de amor e de relacionamentos familiares. Dentro desta clínica - e acompanhando a vida pessoal e o trabalho destas obstetras - são apresentadas inúmeras situações de família, maternidade, paternidade e nascimentos. Por fim, diante da presença de temas como nascimentos, vida e morte, doenças e afetos, o tom emocional é dominante nas histórias, entremeado, muitas vezes, por narrativas cômicas.

Centrado nas médicas, o enredo central também trata de outras personagens do chamado "elenco fixo", ou seja, personagens da clínica que acompanharam todo o seriado. Nota-se, assim, que a estrutura narrativa tem duas grandes temporalidades - o que se passa com este elenco central, e se desenrola ao longo dos 60 episódios e de seus dois anos de exibição focados nos dramas pessoais e familiares; e, por outro lado, a narrativa de cada episódio e seus conflitos, que são apresentados, desenvolvidos e concluídos em cada episódio de cerca de 45 minutos, através de pequenas narrativas morais sobre corpo, saúde, reprodução. ${ }^{7}$

O material oficial da Globo sobre Mulher (tanto na promoção como nas matérias que relembram, ou no projeto Memória Globo) busca destacar que não se trata de uma proposta educativa estrito senso, ou de simples mensagens informativas. No entanto, é notável como, ao longo das cenas, há, com muita recorrência, informações, explicações e receitas para o comportamento correto, preventivo e de autocuidado. A abordagem dos temas, porém, não é unívoca. Há tendências um pouco diversas de acordo com o autor que escreve cada episódio, e, certamente, trata-se de uma medicina convencional alopática e hospitalar. Há tônicas recorrentes. O seriado como um todo, em inúmeros episódios, reforça a importância de exames preventivos; de se fazer o tratamento certo, da forma indicada pelo médico e, inclusive, em termos de seguir os conselhos 
médicos em outras áreas da vida, além dos cuidados diretos com o corpo e a saúde. Repete-se com frequência, seja nos dramas médicos da clínica e do ambulatório, seja na ordem afetiva das personagens fixas, a importância fundamental do uso do preservativo nas relações sexuais como único método de proteção às DSTs e a AIDS. Por fim, alguns episódios fazem denúncias aos problemas do sistema de saúde pública (e, por vezes, ao sistema privado e de convênios) no Brasil, mas através de personagens inescrupulosos.

Apesar da importância evidente da questão dos partos no espaço da clínica e na conversa das médicas com suas pacientes, os temas de saúde reprodutiva e saúde da mulher são muito variados. Buscando uma tentativa de agrupamento por temas, foi possível identificar:

1. contracepção e planejamento familiar (tais como explicações sobre concepção ou contracepção, tratamento de reprodução assistida);

2. gravidez e procriação (um dos focos centrais da trama, com imagens e mensagens sobre exames pré-natal, e, mesmo, pré-nupciais, formas de partos, cuidados na gravidez, amamentação, puerpério, relações de pais e mães com filhos recém-nascidos ou com crianças pequenas);

3. prevenção de doenças (e explicações sobre sintomas e tratamentos, desde DST/Aids, mas, também, como foco explícito nos tipos de câncer femininos, e em doenças variadas);

4. sexualidade e práticas heterossexuais (tanto relacionadas a doenças e distúrbios, como à noção de prazer e de busca de conhecimento do próprio corpo pelas mulheres);

5. empecilhos para o tratamento médico (tabus morais e religiosos, automedicação, recusa de aceitação da doença);

6. trabalho feminino (e os conflitos entre trabalho e maternidade, ou trabalho e família, a busca da realização através do trabalho);

7. direitos das mulheres (tais como direitos trabalhistas diante da gravidez, direito ao aborto em alguns casos e a falta de acesso a ele em outros, direito a não violência na relação conjugal).

Estas são temáticas tratadas numa estrutura narrativa específica do merchandising social, naquelas cenas em que há um tom pedagógico explícito - quer seja de explicação de doenças e tratamento, de promoção de atitudes de prevenção e cuidados de si, de combate de preconceitos, de informação sobre direitos. Na sua grande maioria, estas cenas trazem um personagem do "bem", um profissional capacitado, com saber legítimo para explicar e indicar as atitudes mais corretas na questão tratada, que dá explica- 
ções, em tom didático, para outros personagens que buscam entender e precisam de orientação sobre como agir (consigo ou com outros de sua família).

A dissertação de Alejandra Pía NICOLOSI (2009) explora como se dá este tom pedagógico explícito do merchandising social nas telenovelas da década de 1990 , tal como a fala de um personagem que personifica um saber legitimado, a atenção de outros personagens que precisam ou se interessam pela informação. Em algumas situações, inclusive, personagens do "mal" não compreendem ou rebatem preconceituosa e negativamente a informação oferecida pelo personagem "do bem", que tem o saber legítimo para tratar da questão e concluir. Na maior parte das vezes, nas novelas analisadas por Nicolosi, predominam mensagens médicas, com especialistas da área de saúde (médicos, psiquiatras, psicólogos e enfermeiros) trazendo as informações e indicando procedimentos.

No entanto, no seriado Mulher, pela recorrência de algumas destas mensagens, elas nem sempre são verbalizadas explicitamente, mas é o desenvolvimento da narrativa que ressalta a mensagem de prevenção e destaca a necessidade de seguir o conselho dos médicos. Há, normalmente, mensagens mais detalhadas e explicativas sobre o funcionamento do corpo feminino ou sobre doenças e prevenção, entremeadas de noções mais gerais que, ao se repetirem ao longo de todo episódio, podem ser analisadas, também, como mensagens recorrentes. Uma destas mensagens recorrentes é o uso de preservativos como método de prevenção (às DSTs ou como contraceptivo), ainda que isso seja apenas indicado em imagens em inúmeros episódios, sem ser um tema verbalizado em todos eles, como uma cena recorrente ao longo dos episódios que indica um casal heterossexual que vai ter relações sexuais e um deles abre uma embalagem do preservativo, mostrando seu uso como algo natural e, até mesmo, divertido.

Em todo seriado, são muito naturalizadas imagens das tecnologias de ponta, de tratamentos ultramodernos, uso de grande diversidade de tecnologia médica. Há, também, a promoção de consumo de exames, tratamentos de reprodução assistida, medicamentos e tratamentos psicológicos. E, por fim, há, também, inúmeras cenas em salas de cirurgia e leitos de UTI, ambos repletos de aparelhos.

Nem sempre os aparelhos ou a tecnologia são exaltados no mesmo sentido que o merchandising social, que visa promover a noção de exames preventivos. Mas a visibilidade da clínica moderna e arrojada, os aparelhos de último tipo, os pacientes de classe alta e bem vestidos demonstram, visivelmente, a importância da tecnologia e sua qualidade. A terminologia médica também é fortemente 
presente; em alguns episódios, os termos são explicados pela situação de uso - como a situação em que alguma médica explica à paciente o que se passa com ela; em outros, os termos são mencionados sem muitas explicações aos leigos.

Nas matérias da imprensa escrita e nas entrevistas com profissionais do seriado, inclusive com as atrizes que vivem as protagonistas, se destaca que, apesar do foco ser entretenimento, Mulher seria capaz de "passar informações" à população e ter uma "função social" relevante. Certamente são estes diálogos mais explicativos que se imagina como educativo, mas considero que também todo o apelo ao consumo de tecnologia médica tem, também, uma função de educação (afetiva) para o consumo.

Muitos são os temas que poderiam ser considerados associados à pauta feminista: aborto e direitos reprodutivos, violência doméstica, sexualidade, relações de trabalho, violência sexual, orgasmo feminino. Numa certa medida, nem sempre o tratamento do tema é simpático a algum tipo de abordagem feminista, ou seja, crítico às desigualdades entre homens e mulheres. Por exemplo, embora as médicas do seriado não tenham jamais feito algum aborto, socorrem e cuidam respeitosamente de pacientes que sofriam as sequelas de abortos feitos em condições precárias, e nunca as julgaram ou criticaram pelo aborto, mas não defendem a legalização e nem a descriminalização abertamente. Ou seja, o tom é muito moderado e jamais politizado.

\section{Contexto político que promove as narrativas - A promoção dos partos naturais (hospitalares)}

O período de produção do seriado (iniciado na normalmente um ano antes de sua exibição) é o mesmo da ampliação do debate público em torno do excesso de cesarianas no país. A partir de meados dos anos 1990, o Ministério da Saúde buscou promover partos naturais e diminuir a taxa de cesáreas, estimulando, inclusive, a chamada "humanização" do parto. Em 1996, o governo federal iniciou uma série de iniciativas: uma campanha, promovida pelo Conselho Federal de Medicina, com o apoio do Ministério da Saúde, chamada "Normal é natural"; medidas visando melhorar a assistência ao parto no SUS, com inclusão do pagamento de anestesia para parto normal no sistema; incentivo e regulamentação para criação de Centros de Partos Normal; e o incentivo à capacitação de enfermeiras obstetras e parteiras tradicionais. Em 1996, a OMS já havia lançado uma publicação de assistência ao parto normal (que só foi traduzida pelo Ministério em 2000), visando promover o parto natural em vários países do mundo. 
${ }^{8}$ Agradeço à Sonia Hotimsky por essa e outras informações acerca do debate sobre humanização do parto. Envolvida com o tema, e tendo escrito seu mestrado e doutorado sobre a questão, Sonia assistiu a alguns episódios do seriado a meu pedido, e me ajudou a entender que, ali, a ênfase está no parto vaginal hospitalar, mas muitos procedimentos usados pelas duas heroínas da narrativa não estão de acordo com as cartilhas do atendimento humanizado, uma vez que fazem uso de várias intervenções medicalizantes. Há uma extensa bibliografia sobre o tema no Brasil, sobre a polêmica entre a medicalização e o excesso de intervenções e cesáreas, as iniciativas a favor da humanização e das parteiras, as reações da FEBRASGO e dos Conselhos de Medicina, muitas vezes tentando manter seu filão no mercado, e recusando o atendimento de enfermeiras obstetrizes etc. Cf., entre outros, Sonia HOTIMSKY (2007 e 2001); Carmen Susana TORNQUIST (2002 e 2003): e, sob uma abordagem da medicina, o muito citado artigo de autoria de Aníbal FAÚNDES José Guilherme CECATTI (1991).
Essas iniciativas contaram com o apoio da Organização Mundial da Saúde (que, desde 1985, vinha promovendo partos naturais) e, mesmo, do Banco Mundial, além da forte atuação de ONGs e grupos feministas (tais como Rede Feminista de Saúde e Direitos Reprodutivos, Rede pela Humanização do Parto e Nascimento - REHUNA, Rede de Parteiras Tradicionais, entre outros). As associações profissionais (Federação Brasileira das Sociedades de Ginecologia e Obstetrícia - FEBRASGO, Conselhos Federal e Regional de Medicina - especialmente o de São Paulo - e a Associação Brasileira de Obstetrizes e Enfermeiras Obstetras - ABENFO) também vinham atuando fortemente no debate desde esse período.

Ainda que eu não tenha conseguido uma confirmação da emissora, há evidências de que a produção do seriado Mulher teria sido estimulada em diálogo com essas iniciativas, e, talvez, até diante de uma demanda do Ministério da Saúde. Oficialmente, a Globo prefere manter a imagem de que foi uma ideia original de seus profissionais destacados, como Boni (José Bonifácio Sobrinho) e Daniel Filho.

Embora o conteúdo do seriado não estivesse totalmente afinado com as demandas de humanização do parto, ${ }^{8}$ as médicas de Mulher destacam a importância de ter o parto normal como primeira e mais óbvia alternativa, recorrendo às cesáreas apenas quando necessário. Entre os pouco mais de 60 episódios, em 20 deles, ou seja, um terço, há cenas de parto, dos quais 18 são partos naturais, e 9 são cesáreas. Todos partos hospitalares, afinal, é esse o ambiente da narrativa, que também é afinado com o discurso médicohospitalar e interventivo. No entanto, dada a presença massiva de tecnologia médica e de ponta-exames de ultrassom e laboratoriais de último tipo, salas de UTI e de cirurgia altamente equipadas, menção a tratamentos recentes, como de reprodução assistida -, é de se notar a priorização no discurso e na prática das médicas do parto normal.

Inclusive, a postura difere da do ginecologista, que é apontado como a referência bibliográfica da série. Nos créditos finais de alguns episódios do ano de 1998 (e do último, em 1999), aparece a seguinte informação: "Assessoria Médica: Dra. Tatiana Sampaio, Dr. Malcolm Montgomery, Dr. Fernando Leite, Dra. Cíntia C. de Castro".

Entretanto, nas matérias da imprensa escrita jornais impressos) e sites da internet, o ginecologista Malcolm MONTGOMERY (1997) é o mais citado como consultor médico central ao seriado, e seu livro é divulgado como o material que inspirou o seriado. Malcolm Montgomery define-se como um homem feminista em luta contra o machismo da sociedade contemporânea. Faz inúmeros elogios à força e à natureza 


\footnotetext{
${ }^{9}$ Sobre essa tentativa de autores de TV de tratarem de temas polêmicos buscando agradar a um público amplo, mostrando os dois lados da questão e propondo um "meio termo", veja a análise sobre o tema políitico da questão agrária na novela O Rei do Gado, de 1996-1997, em (2003) e La Pastina et al. (1999).
}

feminina, e revela uma visão bastante essencialista quanto à experiência feminina, destacando como vários aspectos são baseados numa natureza biológica. O livro tem um discurso diretamente favorável à cesariana, como um método mais seguro e com menos riscos, desde que seja esperada a hora certa e não se busque apressar o parto. Por outro lado em sua evidente postura de compreensão da ansiedade de uma mulher diante do parto e do nascimento, destaca a necessidade de um bom atendimento, a importância do alívio à dor (destacando a terrível situação de mulheres no atendimento público não terem direito à anestesia no parto vaginal), e destaca que o bom médico deve saber ouvir sua paciente. Para Montgomery (1997, p. 143), é ela que deve escolher o tipo de parto, estando bem informada.

Nota-se, assim, que, diante de duas posições distintas - a que defende a cesariana como um método mais seguro e que medicaliza o parto com base num discurso de risco e segurança, em contraposição à defesa do parto natural humanizado e as tentativas do Ministério da Saúde de reverter um quadro supostamente "vergonhoso" do país diante da OMS, o seriado aparece dialogando com a questão, sem explicitar essas posições, e, do meu ponto de vista, trazendo uma postura intermediária. Essa tentativa de conciliar visões distintas, tentando agradar, ou, pelo menos, não se opor diretamente aos dois extremos da polêmica, é muito comum nos temas mais políticos tratados pelas telenovelas. ${ }^{9}$ Minha interpretação é que tal fato se deve à amplitude da audiência de TV e a necessidade de uma emissora como a Globo de agradar a públicos distintos. No entanto, o que pude observar quando fiz estudo de audiência (2003) é que essa postura supostamente intermediária parece coerente àqueles espectadores que não conhecem muito da questão tratada, mas desagrada àqueles que são bem informados sobre o tema e que se filiam a um dos polos do debate. A abordagem remete ao objetivo do merchandising social de ser "informativo" e "educativo", pois pretende, exatamente, atingir aqueles espectadores que estariam mais desinformados sobre o tema.

A opção do parto normal é sempre tratada como a primeira e mais "natural" opção das doutoras Cris e Marta, as protagonistas, especialmente quando discutem o tema com suas pacientes. Altamente dedicadas à profissão, a salvar vidas, à missão da medicina, e dispensando sempre o maior cuidado às pacientes, não se queixam de partos nas madrugadas ou em outros horários inconvenientes. Inclusive, a dedicação de Dra. Marta à medicina é parte de sua dificuldade de lidar com a família e do fato de não ser considerada uma "boa mãe" para seu filho (interpretado pelo ator Maurício Mattar). A opção pelo parto normal, no 
10 Tal como a campanha anual "Criança esperança" (desde 1986) e "Ação Global" (desde 1992).

\footnotetext{
${ }^{11}$ Segundo a homepage www.po pulationmedia.org, a PMC é uma organização não governamental sediada nos Estados Unidos, que tem o objetivo de promover o uso de programas de entretenimento dos meios de comunicação como forma de veicular mensagens sociais. Os temas mais promovidos por esta ONG estão de acordo com a noção de que o desenvolvimento passa pela queda de fecundidade e, assim, prioriza questões relativas ao planejamento familiar.

${ }^{12}$ Durante a década de exibição das telenovelas de Sabido, então diretor de pesquisas da Televisa de 1977 a 1986, a taxa de crescimento populacional no México caiu $34 \%$. Além das várias novelas promoverem o valor do planejamento familiar, a necessidade de controle das mulheres sobre seu corpo, e a ideia de que os maridos deveriam cooperar, as novelas acompanharam os esforços de promoção de contraceptivos e informações sobre eles do Conselho Nacional de População no México (Population Media Center)
}

entanto, é contrabalançada por todos os casos de alto risco, que permitem boa dose de dramaticidade à narrativa, que terminam em cesarianas complicadas. O atendimento do parto normal da clínica não segue à risca a cartilha do parto humanizado, sendo retratados partos com várias intervenções medicalizadas.

As cenas de nascimento, porém, permitem momentos de grande emoção à narrativa e sua recorrência parece inevitável num seriado como este. Os grandes dramas e de vida e morte, e inclusive de morte ou risco de morte a partir ou diante de uma situação de nascimento (risco de ou morte da mãe, ou de um bebê prematuro, ou doente), são muito recorrentemente explorados nesse seriado, gerando episódios de grande tensão e afetividade.

\section{Merchandising social}

Na época de exibição do seriado, a emissora tinha formado um departamento de marketing social que visa promover ações sociais que melhorem a imagem da emissora, vinculando-a a algum tipo de promoção social. ${ }^{10}$ No final dos anos 1980, a Rede Globo instituiu de modo crescente a perspectiva de sugerir aos autores de novelas que inserissem "mensagens socioeducativas" em suas narrativas, de modo a promover valores positivos e uma vaga noção de desenvolvimento social. Em meados dos anos 80 , Marcio Schiavo, profissional ligado à ONG norte-americana "Population Media Center"," buscava levar a outros países a metodologia desenvolvida por Miguel Sabido, no México, junto à Televisa. Na década de 70 , Sabido criara várias narrativas consideradas de "educação-entretenimento", que visavam à promoção de valores como "status das mulheres, harmonia familiar, comunicação entre esposos e desenvolvimento infantil", com foco muitas vezes no planejamento familiar e acesso à contracepção. ${ }^{12}$

A metodologia de Sabido referia-se a novelas que eram produzidas com objetivos de promoção do desenvolvimento, e suas técnicas foram exportadas, por exemplo, para a Índia e o Quênia, igualmente com o objetivo de promover o planejamento familiar (Arving SINGHAL, Everett ROGERS e William BROWN in Anamaria FADUL (Ed.). (1993)). Envolvidos com o reconhecimento de que a mídia pode ter efeitos sociais importantes, os autores que desenvolveram telenovelas para educação-entretenimento se voltaram especificamente para grandes questões sociais - planejamento familiar, a igualdade de gênero, atitudes médico-preventivas e prevenção ao HIV/ Aids.

O objetivo do Population Media Center era levar a metodologia de Sabido para todas as partes do mundo, 
especialmente os países "mais necessitados", com foco na questão da população, promover diminuição das taxas de fecundidade é, certamente, um dos principais objetivos, mas tal questão aparece ao lado da problemática da desigualdade de gênero, e, mais recentemente, da prevenção a DSTs/ Aids. "Using the media to motivate family planning, AIDS prevention and respect for women" é o subtítulo da apresentação do site do PMC. O texto no site faz uma associação direta entre crescimento populacional e pobreza, ressaltando a importância de se mudar as posições culturais nesses países em desenvolvimento.

Como afirmei acima, os profissionais da Globo buscam destacar que esse seriado e suas ações de merchandising social nada têm a ver com a proposta de educaçãoentretenimento de Sabido no México e desenvolvida, também, em outras partes do mundo. De fato, o modelo de educaçãoentretenimento estrito senso prevê uma integração entre mensagens exibidas pela mídia (tais como as tele ou radionovelas), e ações de intervenção social mais direta, coordenadas junto a outras instituições, tais como governos, escolas, ONGs. Certamente, não é esse o merchandising social da emissora; a "metodologia" de Sabido, estrito senso, não é visível nas novelas da Globo, nem mesmo no seriado. No material da Globo, as mensagens parecem ser um pouco mais sutis do que no modelo de Sabido, mas o diálogo com as noções desenvolvidas por autores da corrente de educação-entretenimento é evidente.

A crescente inserção de merchandising social nas narrativas da emissora a partir dos anos 90 é notável. De 1995 a 2005, segundo Marcio SCHIAVO (2006), teriam sido promovidas nas novelas da Globo, em parceria com a Comunicarte, cerca de 10 mil ações de merchandising social em 46 telenovelas. Mas este profissional "infla" essa presença, somando qualquer mensagem mais ou menos informativa como merchandising. Nicolosi (2009), que, em sua dissertação de mestrado, busca fazer uma análise mais cuidadosa, considerando como tais apenas mensagens com ações pedagógicas deliberadas e explícitas. Ela contabiliza tal presença em 31 novelas - desde Vale Tudo, em 1989.

Alguns autores de novelas parecem ter sido pródigos em inserções de merchandising social (tais como Gloria Perez e Manoel Carlos), mas este seriado condensou inúmeras iniciativas e pode ser entendido como uma espécie de narrativa de educação-entretenimento.

\section{Dramas femininos}

Há, também, outro nível de sentidos simbólicos do seriado. Se sairmos na interpretação das mensagens mais 
explicitamente "educativas" do seriado, a trama dos dois anos dos personagens centrais se assemelha muito a uma telenovela e traz uma continuidade e um planejamento geral muito evidente. Ao longo dos dois anos, a dedicadíssima Dra. Marta tenta se aposentar e deixar a clínica, o que só acontece, de fato, ao final, depois de vários problemas de saúde. Seu marido, Otávio (Carlos Zara), é retratado como um homem que sempre compreendeu a dedicação quase religiosa da esposa pela medicina e pelo cuidado que dedica às pacientes. Ao longo dos episódios, no entanto, ele se cansa de esperar, e algumas separações temporárias acontecem entre o casal, principalmente num momento de grande sofrimento para o casal com a morte do único filho.

A relação com o filho, Carlos (Maurício Mattar), também é conflituosa. Ele acusa Dra. Marta de nunca ter sido uma boa mãe, pois sempre teria se dedicado mais à medicina. Ela mesma reconhece ter se dedicado pouco ao filho e ao marido. No início do segundo ano, perde o filho num acidente. A história da Dra. Marta é, portanto, a de uma mulher concentrada no trabalho e em suas pacientes, o que é retratado de modo simpático à personagem, mostrando seus conflitos internos e culpas, mas, também, sua eficiência e capacidade de tratar, curar e salvar vidas. Trata-se, assim, de uma médica muito ética, e um modelo feminino dedicado à vida profissional e ao espaço da clínica. Ela própria se torna, inclusive, paciente: enfrenta um câncer e retira parte de uma mama. No segundo ano, sofre um enfarte e uma intervenção cardíaca. Nesse segundo ano, depois de perder o filho, Dra Marta é obrigada a se cuidar um pouco mais e passa, também, a se dedicar aos netos. Ainda assim, a tônica dominante é sua dedicação à medicina, e mesmo pouco depois de uma intervenção cirúrgica cardíaca, corre à clínica para fazer o difícil parto de sua melhor amiga, Dra. Cris, no último episódio da série.

Dra. Cris é uma jovem médica que foi de Belo Horizonte para o Rio de Janeiro, e é contratada por Dra. Marta na esperança de que possa substituí-la quando se aposentar. Trabalham juntas ao longo do primeiro ano, e, no segundo ano, Dra. Marta, depois de longas férias numa viagem de barco com seu marido, começa a se retirar um pouco e Cris assume a direção da clínica. Cris mora com uma amiga advogada, Shirley (Carla Daniel), e esta personagem permite que várias questões que têm desdobramentos entre a medicina e a lei sejam abordadas, sempre tentando defender pessoas em situações desfavoráveis. Shirley será consultada por Cris em vários episódios, quanto à legislação (por exemplo, no episódio sobre eutanásia e noutro sobre aborto), além de ser consultada, também, pelas pacientes 
sobre seus problemas, como o caso de uma jovem que, grávida, está ameaçada de perder o emprego.

Cris representa as experiências de uma jovem profissional competente e dedicada ao trabalho, solteira e sem filhos, mas que busca o amor. Vive algumas paixões frustradas no primeiro ano da série, inclusive com Carlos, filho da Dra. Marta, e, no segundo ano, conquista lentamente um namorado, Dr. João Pedro (Alexandre Borges), pai separado que cria sozinho uma filha, médico idealista e dedicado à medicina e aos pacientes do ambulatório, preferindo atender pessoas das classes populares do que ficar numa clínica de "ricos". No segundo ano da série, também Shirley ganha um namorado fixo, André (Eduardo Galvão).

Por morarem juntas e serem muito amigas, Cris e Shirley falam de inúmeros temas, como amor, sexo, amizades, corpo, saúde, legislação e direitos. Com André, Shirley mantém relações sem proteção e a suspeita de terem contraído HIV é tema de um dos episódios em que o discurso de Cris reforça a necessidade do uso de preservativo em todas as relações sexuais. A mensagem é reforçada por Cris em todos os seus casos amorosos e relações sexuais passageiras em que a cena de sexo é sempre precedida por falas ou gestos que demonstram o uso do preservativo. Mesmo usando preservativo, a própria Dra Cris engravida de um caso amoroso passageiro, explicando, aí, os limites em termos de prevenção à gravidez. Cris pensa em abortar, mas, depois, resolve ter o filho. A situação se resolve quando ela perde o bebê, ainda no início da gravidez, o que a deixa muito triste, e, como em inúmeras novelas, evita que se tematize a gravidez não desejada e a intenção de abortar com mais seriedade, resolvendo o conflito com um aborto espontâneo.

Afrânio (Cássio Gabus Mendes) é o proprietário da clínica, jovem herdeiro de um pai dedicado à medicina, e um antagonista patético (e, muitas vezes, bastante cômico), que se torna mais simpático ao final da série. Tenta economizar e lucrar a qualquer custo, usando de procedimentos como superfaturar os custos e fraudar o SUS; não quer manter o ambulatório que faz atendimento gratuito e popular, discute inúmeras vezes com as médicas protagonistas, opondo-se a elas. Mas nunca as demite e sente depender muito do prestígio da Dra. Marta para manter sua clínica. Afrânio constitui o antagonista em alguns episódios e, também, ao longo da história mais central da clínica. É um personagem cômico, que representa os interesses e o poder capitalista na medicina. Tem uma vida sexual repleta de peripécias engraçadas, e usa sempre preservativos nas relações sexuais. Em um episódio, sofre de certa dificuldade de ereção, tema tratado de maneira 
cômica, mas com explicações médicas cuidadosas sobre disfunção erétil - tema que aparece cerca de 3 ou 4 vezes ao longo dos dois anos, em um deles com um discreto merchandising comercial da Pfizer no consultório de um urologista. Outros profissionais da clínica constituem o núcleo de classe popular, como os enfermeiros Amaury (Paulo Barbosa) e Telma (Lúcia Alves), e o taxista Nilo (Ricardo Pavão). Em alguns momentos, suas histórias pessoais são abordadas, por vezes intrincadas a questões de saúde.

O melodrama supõe, sempre, uma oposição entre o bem e o mal, mas eles nem sempre são corporificados em personagens, se pensarmos na abordagem de Brooks. A oposição entre personagens do bem e do mal em Mulheres é somada ao contraponto humorístico, também muito comum no melodrama (THOMASSEAU, 1989 e MEYER, 1996), representado por Afrânio. Ele personifica tanto a dissimulação em nome de sua ganância e busca do lucro, como um escape de humor que se segue a cenas mais tensas, ou aos dramas mais trágicos da clínica. Há, também, outras personagens que permitem o riso com mais facilidade, como Shirley e a enfermeira Telma. Em diversas cenas de conflito com Afrânio, Dra. Cris revela em seu rosto o quanto se incomoda. Sua expressão transparece diretamente seu incômodo com o proprietário da clínica. Também em outras cenas de conflitos com as pacientes e seus acompanhantes, muitas vezes, seus maridos, Cris evidencia seus sentimentos e impressões, assim como o faz, ainda que de modo um pouco mais discreto, Dra. Marta. Os personagens do bem são sempre marcados por uma clareza de intenções, expressam diretamente o que sentem e pensam, são transparentes e naturais. A moralidade, aqui, torna-se, visível no corpo, no olhar, nos gestos: a inocência e o bem são corporificados em determinados personagens.

Retomando a interpretação de Brooks, nas palavras de Ismail Xavier (2003),

se a moral do gênero [melodrama] supõe conflitos, sem nuanças, entre bem e mal, se oferece uma imagem simples demais para os valores partilhados, isto se deve a que sua vocação é oferecer matrizes aparentemente sólidas de avaliação da experiência num mundo tremendamente instável, porque capitalista na ordem econômica, pós-sagrado no terreno da luta política (sem a antiga autoridade do rei ou da Igreja) e sem o mesmo rigor normativo no terreno da estética. Flexível, capaz de rápidas adaptações, o melodrama formaliza um imaginário que busca sempre dar corpo à moral, torná-la visível, quando esta parece ter perdido seus alicerces. Provê a sociedade de uma pedagogia do certo e do errado 


\begin{abstract}
${ }^{13}$ Xavier (2000 e 2003), inclusive, dá exemplos de estruturas melodramáticas mesmo no cinema de autores, como Fassbinder. Sobre a feminilização do gênero melodramático, cf. Modleski (1982) e Gledhill (1987); sobre a feminilização da soap opera, cf. Ang (1985 e 1990), e, da telenovela brasileira cf. Huyssen (1986) sobre a feminilização da cultura de massa.
\end{abstract}

que não exige uma explicação racional do mundo, confiando na intuição e nos sentimentos 'naturais' do indivíduo na lida com dramas que envolvem, quase sempre, laços de família (p. 91 [itálicos no original]).

Xavier destaca, todavia, que, ao longo do século XX, as mudanças sociais promoveram um imaginário marcado pela psicologia moderna e pela lógica de uma sociedade capitalista e de consumo. Em muito da produção cultural contemporânea, o conflito entre bem e mal é explicitado na oposição entre pessoas autênticas e hipócritas:

Em termos retóricos, isso significa que é essencial, na composição do drama, colocar os autênticos do 'nosso' lado e os hipócritas do lado oposto, regra geral posta em prática nas várias faixas do espectro ideológico, pois todos no melodrama procuram identificar os seus valores sociais com a celebração da espontaneidade e o ataque à dissimulação (XAVIER, 2003, p. 95).

Estas convenções narrativas acerca da oposição entre bem e mal em seus novos e discretos formatos que Xavier destaca são evidentes no caso das médicas protagonistas de Mulher. Entretanto, há uma possível afinidade com este esquema de Xavier, que analisa o gênero narrativo de forma ampla, e não o reduz aos exemplos clássicos e caricatos de melodrama, nem mesmo se atendo aos bens culturais femininos. ${ }^{13} \mathrm{O}$ interesse deste seriado é que, dada a maleabilidade do gênero narrativo, pode assumir integralmente um objetivo de educativo e civilizatório, usando de elementos melodramáticos. São especialmente os personagens associados ao "bem" que trarão as explicações médicas.

$\mathrm{E}$, dentro do esquema do melodrama televisivo, o final dos dois anos do seriado deve culminar com o final feliz das personagens centrais. Dra. Cris é uma protagonista cuja vida profissional e liberdade sexual são um dado do início. Sua busca é pelo grande amor e sua narrativa se completa com o final feliz da maternidade, ainda que não num casamento convencional. Cris e Shirley são mulheres profissionais e independentes, que têm uma variada vida sexual até encontrarem os namorados ideais, com quem gostariam de se casar. Shirley chega mesmo a ficar noiva de André. Mas não há cena de casamento, aliás, não há casamento algum - o que consolida tais relações é o desejo por filhos. Cris e Shirley engravidam nos últimos três episódios, e as cenas de parto e de nascimento coroam o episódio final. Só depois do nascimento de seus bebês gêmeos, a audiência é informada pelas imagens de preparação do quarto dos bebês que Cris vai morar junto com João Pedro. Até a ruptura da bolsa, Cris ainda está no apartamento que 
divide com Shirley. João Pedro é um pai solteiro, que cria a filha sozinho, e, portanto, também os modelos de família já aparecem como tendo mudanças consolidadas. Ainda assim, a reprodução e os filhos aparecem como elementos tradicionais da completude e felicidade das personagens.

Ao final do seriado, o parto de Cris torna-se de alto risco e é apenas pela intervenção da doutora Marta, recém saída de uma intervenção cardíaca, que o caso não termina em tragédia. A cena final é de Cris com Dra. Marta, agradecendo a ela entre sorrisos e lágrimas. A amizade entre os médicos, mas, particularmente, a amizade entre mulheres, entre Cris e Shirley, por um lado, e Cris e Dra Marta, são as relações mais estáveis, fortes e sinceras no seriado.

O happy end do seriado conjuga a eficiência da medicina e das protagonistas - que "salvam" em partos complicados - com a felicidade do nascimento. Paradoxalmente, o empenho em vocalizar o ideal de parto normal era contrabalançado pelas inúmeras imagens de complicações médicas, particularmente nos partos. A estrutura do seriado médico supõe que parte da tensão dramática das histórias está nas complicações médicas e de saúde. A impressão de que o seriado gostaria de promover no discurso das suas protagonistas - de que partos normais são melhores e mais seguros - acabou, por fim, sendo ambígua, na medida em que há muitas cenas de parto e cesáreas com complicações e riscos, inclusive as cenas finais do parto dos gêmeos de Cris aos cuidados da Dra. Marta. O foco na saúde feminina e na reprodução tornou este seriado bastante heteronormativo, e o final feliz dos nascimentos certamente promoveu o ideal de reprodução e família, mantendo certo clichê narrativo das telenovelas da felicidade completa através da maternidade.

\section{Considerações finais}

Busquei trazer, aqui, uma visão geral do seriado, em termos de temas mais recorrentes e estrutura narrativa sob a qual tais temas costumavam ser tratados ao longo de dois anos de exibição. Para isso, escolhi alguns dos que me parecem representativos do tom dominante do seriado em termos dos aspectos médico-sociais tratados. Também privilegiei os casos que dialogam com a polêmica dos tipos de parto e do excesso de cesáreas no Brasil - polêmica muito visível no período de produção e exibição do seriado, e com a qual ele dialoga de modo explícito e evidente.

Vê-se, ali, o uso de uma estrutura melodramática, em que os personagens do "bem" e com saber legítimo - as heroínas dedicadas, Cris e Marta, mas, também, outros profissionais de saúde da clínica, como o clínico geral Dr. Samuel (Nildo Parente), ou a pediatra Dra. Anair (Mônica Torres) 
e os enfermeiros - explicitam, em suas falas, e em seu comportamento, valores e atitudes que o merchandising social quer promover. A mensagem é reforçada na oposição aos "vilões", aos antagonistas: as doenças e males que afligem suas pacientes (na maioria mulheres); a falta de conhecimento ou ignorância sobre tais doenças e como tratá-las; a falta de prevenção e de atitudes de cuidado de si dessas pacientes; as superstições de vários tipos, inclusive de ordem religiosa, que atrapalham ou impedem os tratamentos clínicos ou o uso correto de contraceptivos; maridos violentos ou autoritários que causam direta ou indiretamente problemas de saúde em suas esposas; ou, mesmo, médicos gananciosos e antiéticos que, por objetivos individuais, põem a saúde das pacientes ou seus bebês em risco. O desenvolvimento da narrativa - como a cura ou o nascimento saudável de uma criança diante da atitude correta, ou a morte ou agravamento da doença, no caso das pacientes que não seguem os conselhos médicos, por exemplo - reforça sempre a "lição moral" que se pretende passar.

A promoção do parto normal (hospitalar), por sua vez, que é um dos focos do seriado, parece ter sido afetada pela lógica do drama médico. Um dos focos do seriado de promover o parto normal (hospitalar) parece ter sido afetado pela lógica do drama médico. As cenas de parto mostram com mais frequência o nascimento como um procedimento de riscos, para o qual as habilidades das protagonistas mostramse inquestionáveis e cuja tensão ajuda no tom dramático do seriado.

Vê-se, em Mulher, uma forte pedagogia do cuidado (médico) de si, mas que traz, junto também, certos ideais de feminilidade. No final dos anos 90 , o foco não é mais a busca da afirmação da independência e do trabalho feminino, considerando que a vida profissional já é um dado para as personagens centrais, e a vida (heteros)sexual já se realiza de modo divertido e, mesmo, variado. O ideal, agora, mostra a busca do encontro amoroso (heteronormativo) de protagonistas que já são mulheres autônomas e profissionais.

Além das mensagens médicas e de cuidado, há uma longa narrativa dramática em torno das personagens centrais, em que o foco está mais voltado a seus dramas pessoais, suas histórias de amor e conflitos familiares, embora possam, em alguns momentos, tratar, também, de questões de saúde (como o câncer de mama de Dra. Marta). E evidentemente há tanto nessa história de "mais longa duração" (dois anos), como nos dramas pessoais mais curtos e entremeados de mensagens médicas, os temas já clássicos da teledramaturgia brasileira - amor e conjugalidade, afetos e desafetos, conflitos da intimidade, relações familiares, encontros e desencontro amorosos. 


\section{Referências}

ABOUT Us. PMC changes behavior to improve the health and well-being of people around the world using entertainment-education. Soap operas, it turns out, can change the world. Population Media Center. Acting for change. Disponível em: https://www.populationmedia.org/about-us/ . Acesso em: 06/2016.

ALMEIDA, Heloisa Buarque de. Telenovela, Consumo e Gênero: "Muitas mais coisas". Bauru: Anpocs / EDUSC, 2003.

ANG, len. Watching Dallas - soap opera and the melodramatic imagination. London: Routledge, 1985.

. "Melodramatic Identifications: television fiction and women's fantasy". In: BROWN, Mary Ellen (Ed.). Television and Women's Culture - the politics of the popular. London: SAGE, 1990.

. Living Room Wars - rethinking media audiences for a postmodern world. London: Routledge, 1996.

BROOKS, Peter. The Melodramatic Imagination: Balzac, Henry James, Melodrama, and the Mode of Excess. New Haven: Yale University Press, 1976.

ELIAS, Norbert. O processo civilizador, 2v. Rio de Janeiro: Jorge Zahar, 1994

FAÚNDES, Aníbal e CECATTI, José Guilherme. "A operação cesárea no Brasil: incidência, tendências, causas, consequências e propostas de ação". Cadernos de Saúde Pública, n. 7, v. 2, p. 150-173, 1991.

FILHO, Daniel et al. O Circo Eletrônico: fazendo TV no Brasil. Rio de Janeiro: Jorge Zahar, 2001.

GLEDHILL, Christine. Home is Where the Heart is - Studies in Melodrama and the Woman's Film. London: British Film Institute, 1987.

HAMBURGER, Esther. O Brasil antenado: a sociedade da novela. Rio de Janeiro: Jorge Zahar, 2005.

HOTIMSKY, Sonia. A formação em obstetrícia: competência e cuidado na atenção ao parto, 2007. Tese (Doutorado em Ciências, Medicina Preventiva), USP, São Paulo.

. Parto e nascimento no ambulatório e na casa de partos da Associação Comunitária Monte Azul: uma abordagem antropológica, 2001. Dissertação (Mestrado em Saúde Pública), USP, São Paulo.

HUYSSEN, Andreas. After the Great Divide: Modernism, Mass Culture, Postmodernism. Bloomington: Indiana University Press, 1986.

LA PASTINA, Antonio; STRAUBHAAR, Joseph; ALMEIDA, Heloisa B. de. "Producers, Audiences and the Limits of Social Marketing on Television: the case of O Rei do Gado, a telenovela about land reform in Brazil". In: 49th INTERNATIONAL COMMUNICATION ASSOCIATION 
CONFERENCE. 26-31 de maio de 1999, San Francisco, Califórnia.

LAURETIS, Teresa de. "A Tecnologia do Gênero". In: HOLLANDA, Heloisa Buarque de. Tendências e impasses: o feminismo como crítica da cultura. Rio de Janeiro: Rocco, 1994.

MEMÓRIA Globo. Autores: Histórias da teledramaturgia, v. 1 e 2. São Paulo: Globo, 2008.

MEYER, Marlise. Folhetim - Uma história. São Paulo: Companhia das Letras, 1996.

MODLESKI, Tania. Loving with a Vengeance: Mass-produced fantasies for women. New York: Methuen, 1982.

MONTGOMERY, Malcolm. Mulher: o Negro do mundo - uma visão científica e humana do universo feminino. São Paulo: Gente, 1997.

NATANSOHN, L. Graciela. "Medicina, gênero e mídia: o programa Mulher da TV Globo". Revista Estudos Feministas, v. 8, n. 1, p. 46-63, 2000.

NICOLOSI, Alejandra Pía. Merchandising social na telenovela brasileira - um diálogo possível entre ficção e reali-dade em Páginas da Vida, 2009. Dissertação (Mestrado), ECAUSP, São Paulo.

OROZ, Silvia. Melodrama: o cinema de lágrimas da América Latina. Rio de Janeiro: Rio Fundo, 1992.

ORTIZ, Renato; BORELLI, Silvia e RAMOS, José Mário. Telenovela - História e Produção. São Paulo: Brasiliense, 1989.

OUR Approach. Population Media Center. Acting for change. Disponível em: https://www.populationmedia.org/ourapproach/. Acesso em: 06/2016.

PALLOTIINI, Renata. Dramaturgia de Televisão. São Paulo: Moderna, 1998.

SCHIAVO, Marcio. "Dez anos de merchandising social". In: XXIX CONGRESSO BRASILEIRO de CIÊNCIAS da COMUNICAÇÃO (INTERCOM). Brasília, 2006. Disponível em: http://www.intercom.org.br/papers/nacionais/2006/ lista_resumos_evento_NFS.htm.

SINGHAL, Arvind; ROGERS, Everett e BROWN, William. "Entertainment Telenovelas for Development: Lessons Learned". In: FADUL, Anamaria (Ed.). Ficção Seriada na TV: as telenovelas latino-americanas. São Paulo: ECA-USP, 1993.

THOMASSEAU, Jean-Marie. El Melodrama. México: Fondo de Cultura Económica, 1989.

TORNQUIST, Carmen Susana. "Paradoxos da Humanização". Cadernos de Saúde Pública, Rio de Janeiro, FIOCRUZ, v. 19, n. supl. 2, p. 107-113, 2003.

"Armadilhas da Nova Era". Revista Estudos Feministas, Florianópolis, v. 10, n. 2, p. 483-492, 2002.

XAVIER, Ismail. "Melodrama ou a sedução moral negociada". Novos Estudos CEBRAP, n. 57, p. 81-90, julho de 2000.

334 Estudos Feministas, Florianópolis, 25(1): 315-335, janeiro-abril/2017 
Body education: the series Mulher and the promotion of educational messages regarding medicine messages

Abstract: This article reflects on a TV series called Mulher (Woman), exhibited by Rede Globo in 1998-1999, in Brazil, targeting female audiences. Particular attention is drawn to the intense social merchandising related to medical and preventive health matters throughout the series. The story of two gynecologists, depicted by means of a melodramatic and comic narrative, promotes messages on female health, valuing ideas concerning the care and medicalization of the body. This text discusses two aspects: the social context as well as the specific period in open $T V$ broadcasting in which this series was produced; and how medical and technological issues are presented. In order to interpret the series' content, the merchandising process as well as its use of a certain melodramatic narrative structure is analyzed.

Key words: media; teledramas; health; gender; social messages.

Heloisa Buarque de Almeida (helobrun@uol.com.br). Possui Graduação em Ciências Sociais pela Universidade de São Paulo (1988), Mestrado em Antropologia pela Universidade de São Paulo (1995) e Doutorado em Ciências Sociais pela Universidade Estadual de Campinas (2001). Atualmente, é professora doutora da Universidade de São Paulo, Coordenadora do Programa de Pós-Graduação em Antropologia Social, tendo coordenado, entre 2014-2015, o programa USP Diversidade, que visa combater as desigualdades de gênero, sexualidade e raça na universidade. Foi membro da Diretoria da Associação Brasileira de Antropologia na gestão 2013-2014, e, atualmente, é membro do Comitê de Gênero e Sexualidade da mesma associação. Tem experiência na área de Antropologia, com ênfase em Antropologia Urbana e Marcadores Sociais da Diferença, atuando, principalmente, nos temas: gênero, mídia, consumo, família, corpo e violência de gênero. 